\title{
Developing an Inclusive K-12 Outreach Model
}

\author{
Karen Nolan \\ Dept. of Computing \\ TU Dublin \\ Dublin, Ireland \\ Karen.Nolan@TUDublin.ie
}

\author{
Roisin Faherty \\ Dept. of Computing \\ TU Dublin \\ Dublin, Ireland \\ Roisin.Faherty@TUDublin.ie
}

\author{
Keith Quille \\ Dept. of Computing \\ TU Dublin \\ Dublin, Ireland \\ Keith.Quille@TUDublin.ie
}

\author{
Brett A. Becker \\ School of Computer Science \\ University College Dublin \\ Dublin, Ireland \\ Brett.Becker@ucd.ie
}

\author{
Susan Bergin \\ Dept. of Computer Science \\ Maynooth University \\ Co Kildare, Ireland \\ Susan.Bergin@mu.ie
}

\begin{abstract}
This paper outlines the longitudinal development of a K-12 outreach model, to promote Computer Science in Ireland. Over a three-year period, it has been piloted to just under $9700 \mathrm{~K}-12$ students from almost every county in Ireland. The model consists of a two-hour camp that introduces students to a range of Computer Science topics: addressing computing perceptions, introduction to coding and exploration of computational thinking. The model incorporates on-site school delivery and is available at no cost to any interested school across Ireland. The pilot study so far collected over 3400 surveys (pre- and post-outreach delivery).

Schools from all over Ireland self-selected to participate, including male only, female only and mixed schools. The no-cost nature of the model meant schools deemed "disadvantaged", to private fee-paying schools participated. Initial findings are very positive, including the balance of male and female participants, where in the 2017-18 academic year it was $56: 44$ and in $2019-20$ (to date), it is 35:65 respectively. Once the model is validated and tweaked (based on survey data), the model will be published (open access) for other institutions to implement the model locally. In addition, the authors intend to link schools (that the team have worked with over the three years) with local institutions, thus developing a sustainable ecosystem for the program to continue. This paper describes the model structure and outlines early findings.
\end{abstract}

\section{CCS CONCEPTS}

- Social and professional topics $\rightarrow$ Computer science education.

\section{KEYWORDS}

Computer Science Education; K-12; Outreach; Computing CampsInclusive; Female Student; Perceptions

Permission to make digital or hard copies of all or part of this work for personal or classroom use is granted without fee provided that copies are not made or distributed for profit or commercial advantage and that copies bear this notice and the full citation on the first page. Copyrights for components of this work owned by others than ACM must be honored. Abstracting with credit is permitted. To copy otherwise, or republish, to post on servers or to redistribute to lists, requires prior specific permission and/or a fee. Request permissions from permissions@acm.org.

ITiCSE '20, June 15-19, 2020, Trondheim, Norway

(C) 2020 Association for Computing Machinery.

ACM ISBN 978-1-4503-6874-2/20/06 . \$15.00

https://doi.org/10.1145/3341525.3387421
ACM Reference Format:

Karen Nolan, Roisin Faherty, Keith Quille, Brett A. Becker, and Susan Bergin. 2020. Developing an Inclusive K-12 Outreach Model. In Proceedings of the 2020 ACM Conference on Innovation and Technology in Computer Science Education (ITiCSE '20), June 15-19, 2020, Trondheim, Norway. ACM, New York, NY, USA, 7 pages. https://doi.org/10.1145/3341525.3387421

\section{INTRODUCTION}

Formal computer science education at the K-12 level in Ireland is a recent development [26, 29]. Currently there are a small number of schools piloting a Computer Science (CS) curriculum at upper second level (typically 16-18 years of age), along with an optional coding short course for lower second level (typically 12-15 years of age), with a primary school curriculum under development.

In reaction to this, some Irish third level institutions are introducing a formal CS teacher training. While in its infancy, this is vital as the majority of teachers in Ireland who are currently teaching, or likely to teach primary and second-level CS, are not qualified in CS to degree level and often have only limited exposure to formal CS (e.g. have completed just basic coding courses). In most third level institutions the course offered for teacher training is a conversion degree, a Higher Diploma, where the aim is that the credits achieved will allow for recognition by the Irish Teaching Council (the official registration body for teachers), to formally teach the incoming subject.

Ireland is a strong player in the global IT industry [2] and there is an ongoing concern about the inability to fill related jobs in the market $[19,32]$. This is compounded with falling numbers pursuing third level CS in Ireland (it fell by $8 \%$ in 2018 alone [8]) and a low female uptake of the subject [28], which is currently about $20 \%$. With the competitive pressures at third level institutions for funding, etc., institutions are implementing outreach models to promote $\mathrm{CS}$, address stereotypes and generally improve perceptions of the subject. Most third level institutions in Ireland run some form of an outreach programme to address these general goals, however in many cases the format, methodology, pedagogical approach, and in particular focus on validation and best practice, differs significantly. This is likely due to limited time constraints or resources. The development of an outreach model to achieve these goals, that could be validated longitudinally, with a large sample size, at a wide number of schools, with different student profiles, would be a valuable contribution to the community. 


\section{RELATED LITERATURE}

aditionally in Ireland, students did not formally study CS in school. This has meant that for the majority of students, they did not have a good understanding of what CS is about and thus struggle to assess if it is a good subject choice for them at tertiary level. Recent findings in an Irish study, indicate that tertiary computing students' sense of belonging differs by gender [23]. This indicates that pre-tertiary outreach can be important in two ways: first by challenging stereotypes prior to the important choice of what to study at third-level, and second, as a mechanism to promote sense of belonging for third-level students that help in K-12 outreach [23] Issues like sense of belonging and course choice are compounded by numerous inaccurate stereotype misconceptions; e.g. CS is for nerds, CS is not for girls etc. which is widely regarded as a key factor in the lack of gender diversity in the computing industry [33] and the focus of increasing research efforts [3, 22]. However, recent studies suggest that outreach programmes can positively affect general uptake at third level and interest in the domain $[25,30]$. To address some of these issues countries have, using a variety of approaches, run outreach programmes for children in K-12. The U.S. has arguably carried out the largest number of outreach programmes having similar issues to those seen in Ireland [24]. In this section, related literature on CS focused outreach models is described, examining in particular their outreach methodologies, participant numbers, inclusive models and outreach research, thus setting the space for this report describing our outreach programme and initial assessment of its impact.

\subsection{Outreach Methodologies}

In general most outreach programmes focus on students attending a college campus for hands-on practical workshops in different aspects of CS [13,14, 16, 21]. Typically workshops use interactive problems to engage students with mostly online tools. In the middle east, Qatar, in conjunction with Carnegie Mellon University, ran outreach programs aimed at increasing CS uptake that were composed of three workshops over 1.5 days once a year on problem solving and programming [30]. Of most note, two of the outreach programmes reviewed were delivered directly at schools, with the goals of increasing understanding of CS related courses and career paths as well as tackling misconceptions [25, 27]. One programme ran two "roadshows" where students were shown diverse research projects by undergraduates, given a tour of the college, had a talk by the head of the faculty and were offered a Q\&A session. Students in this programme were not exposed to any hands-on CS related work in either workshop [27]. The other programme used a combination of activities targeted at females: competitions, clubs, conferences, classroom workshops (roadshows), and summer camps [25].

\subsection{Inclusive Outreach}

The Cambridge Dictionary defines Inclusive Outreach as "An inclusive group or organisation tries to include many different types of people and treat them all fairly and equally" [1]. In the K-12 space inclusive outreach should at a minimum include: gender (in particular female students, due to the low female uptake at third level of about $20 \%$ [28]), as well as disadvantaged and rural schools (schools outside the metro areas that may have limited or no access to third level institutions or outreach). The literature reports outreach models that may not fully satisfy these criteria, or do not report in detail the model or student responses. This is a concern outlined in a review of outreach camps by Decker [7].

One programme specifically targeted those who excelled at maths, but had not been exposed to CS [9]. Another interesting finding was that in all the outreach programmes researched few noted how the students for these camps were recruited. Only one programme had an open call, which was however restricted geographically to three local area schools [25]. Due to low female uptake of CS [28], some outreach models focused on female only outreach activities [25], or were largely female attended [15]. A study by Kamberi reported that running all-female outreach programmes may not be optimal [18]. This programme ran two Java programming summer camps, one as a mixed-gender and the other as all-female. Local area schools participated and the camps were open to any student between the age of 13-17 years. Students chose to opt in. Some of the questions the students were asked focused on their perceptions around gender bias, and some on whether the student had a preference for all-female or mixed-gender camps. They reported that there was no difference between the two groups on the questions presented.

The studies found in the literature, while perhaps trying to be inclusive, in many cases selected student groups (such as high mathematical achievers or female students) or did not report recruitment techniques. Thus it is difficult to generalise on the findings of these studies, and to their value for an inclusive outreach camp model.

\subsection{Outreach Research}

A significant number of the programmes surveyed the students before and after $[9,13,27]$. The results were generally positive, with students feeling they were more aware of what CS involved and more confident to attempt programming and other CS related activities. Lakanen [20] noted interestingly, that students who choose to attend the programme themselves, did better than those who were sent by their parents. One programme found that from their post-enrolment surveys, the number of CS program and university applicants increased, arguably due to their outreach efforts [30], however details are not provided. The research collected during an outreach roadshow [25], recorded a $66 \%$ increase in the number of students that reported being "super" interested in CS.

\subsection{A Common Framework}

In 2017 a review on outreach programmes worldwide entitled "Towards a common framework for evaluating computing outreach activities." [7] was performed. The review included an overview of the literature and highlighted concerns in the current reporting of outreach programmes. It concluded by defining three key broad categories of recommendations for future work.

General findings: The review found that the number of participants reported in each study ranged from 2 to 9999 but most studies had between 20 - 29 participants [7], where only two studies exceeded 4000 students, this is also echoed in the literature reviewed in the following studies [21, 25, 27, 30]. Most of the studies (61 percent) were quantitative in nature [7]. Decker noted that only $8 \%$ of the studies were longitudinal and that "In order to adequately address 
the larger question of the long-term effectiveness of these programs, more longitudinal studies are needed" [7, p630].

Recommendations: First, the review suggested preliminary steps that should be considered on a research based outreach programme. These included defining a research question, ensuring ethical approval for the study, considering external factors that might influence the study and defining the data to be collect so that it can adequately answer the research question. Second, the authors suggest that the data to be collected should contain some consistent key elements including, gender, ethnicity, age and grade in school, unique characteristics that may influence the study, reliable survey instruments and finally have 26 or more participants for validity. Third, the reporting should clearly state the research question or the purpose of the study, describe the activity, provide the length of time of the activity, provide information on who ran the activity, provide data collected together with associated percentages.

When examining the literature and in particular the work by Decker [7], it is clear that the work covered on these outreach programmes are valuable and timely. We aims to address the recommendations of the Decker, McGill \& Settle framework, and the concerns listed in the same report for the initial development of this outreach model. The model presented in this paper will be iteratively developed, longitudinal, and research-based. If this research can provide insights and aid the development of future outreach programmes, this could positively effect discipline uptake in third level, and in turn by association address the shortage of skilled graduates for industry. This paper aims to introduce the model, and highlight its current position (early pilot work) and findings.

\section{THE OUTREACH MODEL}

This initiative has three facets: (i) the development of an outreach model, (ii) provision of professional development (PD) for teachers and (iii) an over-arching focus on a research-led practice. This section looks at the pilot phase of the outreach model and the associated research. Future work will involve a detailed analysis of the pilot phase of the teacher PD and associated research. The outreach model was developed over three years with a pre-pilot in the first year 2017-18, the model deployed in pilot phase in 20182019 , and was continued in the current academic year of 2019-20 in an effort to gather longitudinal experience and research/data.

\subsection{Pre-Pilot Outreach Programme}

The goal of the pre-pilot phase was to establish points of contact with schools and to develop ideas of a skeleton model. During this phase the decision to offer a mobile outreach camp evolved. The team understood that in Ireland, as with perhaps most other jurisdictions, funding at $\mathrm{K}-12$ level is almost non-existent and teacher roster time is constrained. Thus, for schools or class groups to travel is difficult (if at all possible), and would typically involve at most one class. This problem is echoed in the literature [6]. Travelling to the school removes the transport and teacher cover costs. Another notable outcome was to develop a camp with a two hour duration, with a typical K-12 class ( $n \sim 24-30$ students). This was mainly to best accommodate school timetabling. Most school days in Ireland are $\sim 6$ hours in length consisting of two hours, followed by a small break, two more hours and then lunch, with typically two hours of class in the afternoon. While this schedule did vary, depending on age group and school requirements, this was the typical schedule. Prior outreach work in other locations have found that workshops consisting of a duration of hours, up to a single day to be successful with one long-lived program delivered by Georgia Tech delivering 3-4 hour workshops [14]. In Ireland, two hours has been found to be effective in CS Sparks, a program that has been running for several years that serves students that are 14-15 years of age [23].

This schedule also allowed the team to run up to three camps per day at a single school, reaching up to 90 students. Word spread (using social media and mailing lists) quickly about the programme and in the first pre-pilot year, 95 schools and $~ 2900$ students participated. The experience of the team delivering the camps was positive and the experience helped identify an initial pedagogical approach. The team did not envision such a large uptake in the first year, thus no research surveys were designed (the aim was to do this at the pilot phase). Within a single year the team had made connections to just under 500 teachers in Ireland, with a considerable number of enquiries for camps the following year.

\subsection{Developing the Pilot Model}

The pilot model and its content were developed from learning and experiences gained through the pre-pilot phase from the pre-pilot pedagogical approaches as described later in this section. The model was tuned and tweaked over the duration of the first year, with modifications and improvements made at regular intervals. The primary goal of the pilot study was to examine the pedagogical approach and content and evaluate effectiveness. Furthermore, the team hoped to positively promote attitudes, perceptions and build student interest in pursuing further study in CS. To reflect this, the camp structure was divided into three sections:

(1) Introduction to the roles and careers of a computer scientist

(2) Hands on coding (using Micro:bit)

(3) Hands on problem solving (using the Bebras challenge)

While these goals are not novel, the development of the model, with underlying research and validation, using a large scale longitudinal study, we believe is. The three sections of the pilot study outreach camp are defined, using widely acknowledged pedagogical approaches where possible, and pilot pedagogy approaches where not, with the aim to examine them over time. In addition, an ITiCSE working group, has developed an enacted curriculum survey, that will measure pedagogical approaches enacted within worldwide curriculum [10-12]. This will be useful to determine pedagogy used internationally to benchmark and provide insights for the pedagogy used in our model.

Introduction to the roles and careers of a computer scientist: This session is short and interactive, typically consisting of a 15-20 minute presentation using visual aids. Initially stereotypical images are shown and the students are asked what they think could be wrong with each image (sample image shown in Figure 1). Identifying stereotypes in the images uses a think pair share approach [17], to encourage critical thinking and group discussion. This was to guide students, to uncover what was missing from the stereotype images, such as working in groups/teams or female computer scientists. Following this discussion, a presentation on the work-related roles and environments available to computer scientists is given. 


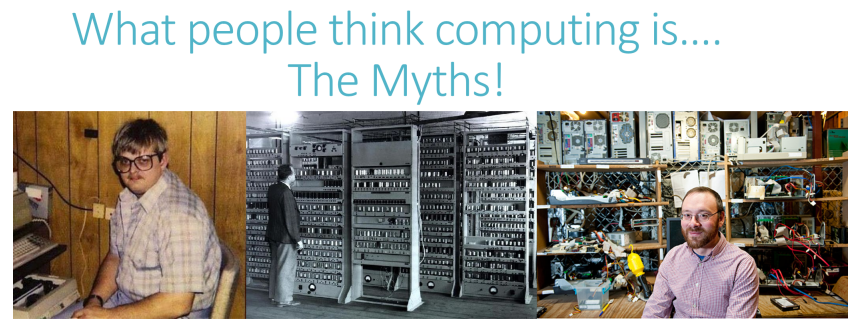

What is missing from this picture?

Figure 1: Image used to promote critical thinking and discussion of CS stereotypes

Hands on coding (Micro:bit): The introduction is followed by a hands-on coding session. Many schools do not have sufficient funding to have well maintained functional computer labs and where they do the labs are not always available for use. To alleviate this dedicated laptops and tablets were purchased for this project to allow the team to visit schools and use regular classrooms to run the camps. The IDE chosen was the MakeCode online $\mathrm{IDE}^{1}$ as seen in Figure 2, This IDE allows programs to be cached, allowing the outreach camp to run even if there was no WiFi available. The IDE uses block-based programming, similar to that of Scratch. The coding session involved activities with increasing levels of difficulty: starting with displaying the students initials on the screen up to and including building and testing a step-counter. The activities used in this session consisted of the following: Modelling; PRIMM [31]; Targeted Programming Tasks (Debugging, Intentional Errors, Fill in the gaps, Worked Examples); Narratives; Paired Programming; Algorithm Design. It is acknowledged that time on task for each of these pedagogy were limited, where the outreach model aimed to expose students to multiple teaching and learning approaches. This was to try and reduce some typical stereotypes such as computer scientists work "on their own in a dark room".

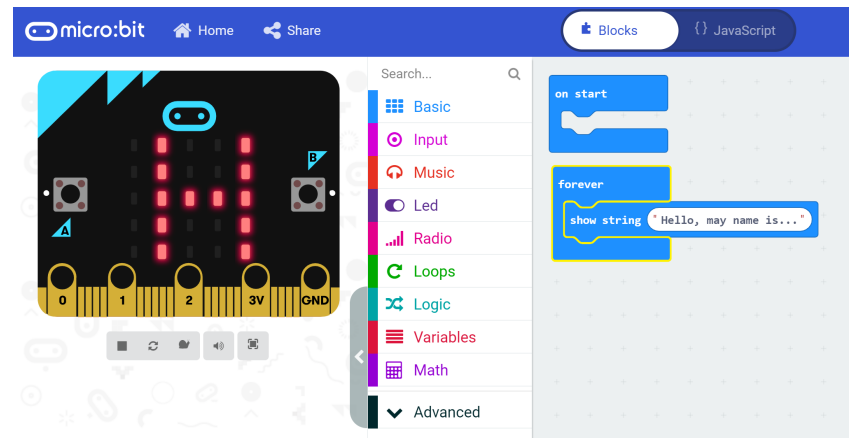

Figure 2: Image of MakeCode Micro:bit IDE

Hands on problem solving (Bebras challenge): Finally, in the last 30 minutes of the outreach session, the students participate in pen and paper activities using problems predominantly sourced from the Bebras challenge $^{2}$ [5], with some additional problems sourced from

\footnotetext{
${ }^{1}$ https://makecode.microbit.org/

${ }^{2}$ Bebras is an international initiative aiming to promote Informatics (CS, or Computing) and computational thinking among school students at all ages.
}

third level. The additional problems aimed to provide differentiation if required, that is for strong students who may have been at risk of getting bored with the typical challenges. A sample Bebras challenge is presented in Figure 3. In this session, students typically attempt four to ten questions, depending on the group and level. After each problem is attempted, it is decomposed and discussed. The activities used in this session consisted of the following (these typically fall under the heading of computational thinking): Algorithm Design; Representation; Computational Thinking; Abstraction.

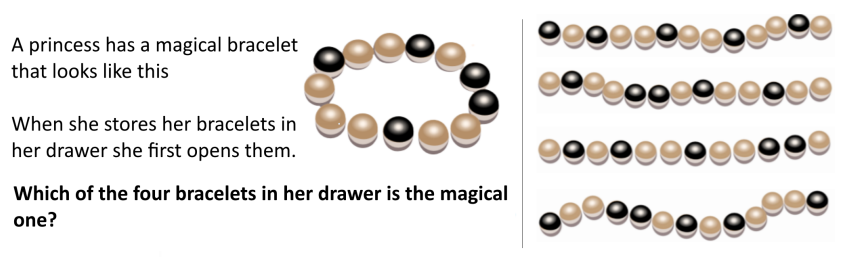

Figure 3: Sample Bebras challenge (typically used at upper primary or lower second level)

\subsection{Outreach Research}

In addition to the outreach session and pedagogy development, the team also captured student survey data. Ethical approval for this research was granted. The preliminary research goals (RG) and questions (RQ) for the outreach model were:

(1) (RG) Promote attitudes, perceptions and interest in pursuing a future in CS with K-12 students.

(2) (RG) Develop, validate and publish the outreach model.

(3) $(\mathrm{RQ})$ Where in the pipeline of K-12 are students disparaged from considering educational/career paths in CS?

(4) (RQ) Can a short intervention (outreach session) positively affect, negative perceptions, attitudes and stereotypes typically associated with CS?

(5) (RQ) Can an outreach programme, such as this increase gender balance, disadvantaged and general uptake of CS over a longitudinal campaign.

Before each outreach visit (approximately one to two weeks prior) parental permission slips, study information and the letter of ethical approval was sent to the school, with only two schools declining to participate in the research survey (they still participated in the outreach camp). The signed parental consent forms were used to identify students who were eligible to take part in the survey. Participating students were given a survey form for the outreach session that they filled partially before the camp and then completed after the camp concluded. As the surveys were anonymous this ensured that the same students completed the same survey. The surveys were then collected at the end of the camp, where the parental consent forms were separated from the surveys to ensure no student was identifiable. In total 3400 surveys have been collected for future analysis.

Prior to the camp: The pre-camp portion of the survey comprised of questions gathering demographic data; behavioural data (such as activity on social media and game playing); maths and science experience and performance; prior knowledge of computing careers; consideration of a career in computing, self-reported ability on using computers; reasons why they might not pursue a computing 
career; role models; family working in computing; and prior computing experience (camps, school etc.). The students are given the pre-camp portion of the survey before any discussion on computing commences to ensure results are not biased. Students are asked to complete the survey alone and to be honest. Anecdotally, in initial surveys it was noticed that students were trying to give "correct" answers for example when asked how long do they spend on social media, in some cases the students were comparing answers with other students. Addressing this early in the outreach session design, has helped in the validity of responses.

Post camp: The post-camp portion was composed of questions asking about having a future career in computing; implications of the camp on their perceptions; facts students did not know about computing; self-perception of programming ability after the camp with a provision for open-ended feedback. The hope is that this section will allow us to investigate if the outreach session has a positive effect on computing perceptions among students who participated. Given the students complete a number of coding tasks as part of the outreach session, insights of students self-perception of their programming abilities may be of value for future outreach development. The team will also be able to draw conclusions in relation to students understanding, or lack of understanding in relation to the general computing space, which in turn will inform future research and outreach development.

3.3.1 Research Summary. This research allows the team to not only capture data from pre-conceptions, but also a snapshot of the effects of the camp, and additional ways to improve the model. This data is currently being analysed with a plan to publish any insights and findings. We also collected data if the school applied for the outreach programme over the three years, and collected a sample teacher survey, investigating multiple factors that may have led to the school selecting the outreach programme. This is again outside the scope of the paper, but will be developed on, in future work.

\section{PILOT OUTREACH OVERVIEW}

From the academic year of 2018-19, the team used an online booking system to allow interested schools to sign up for the camps. This resulted in 160 school visit days for outreach camps for 2018-2019 and 110 for 2019-20. The booking system was advertised on social media, our mailing list and the Computers in Education Society of Ireland (CESI) mailing list [4] and this resulted in a large number of new schools, who were not part of the pre-pilot, opting to participate. It is worth noting that within three days of opening the booking system, every camp was booked (ranging from September 2018 through until June 2019), and the same occurred again with the 2019-20 bookings. On an individual school visit day, the team are able to run one to three outreach sessions per day at each school. This allowed up to $\sim 90$ students to be reached in a single day with three team members running sessions in parallel (typically only one team member generally will attend a school).

Many of the schools who participated were in County Dublin, and given the large population density in this area this was expected. However, the geographical spread was very positive, where the outreached programme reached every county in Ireland (as presented in Figure 4). As previously mentioned the Irish educational system has just introduced an upper second level CS Subject [29]. There are 40 schools selected in phase one (the pilot phase) and with the model, the team ran outreach camps with $2 / 3$ of these schools. It was useful to work with this cohort, as many institutions were trying to access them (mainly for research purposes), given their importance in piloting CS at second level in Ireland. Further attention will be given to this cohort as part of the analysis of the research surveys. Findings here may help inform other jurisdictions who are also embarking on formal upper second level CS curricula.

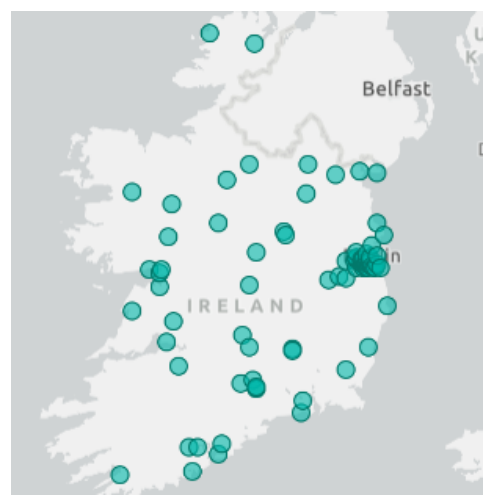

Figure 4: Geographical spread of school visits for 2019/2020

In the literature when studies refer to outreach numbers, it is usually in terms of school days or even perhaps schools. Sometimes this does not paint the entire picture. This works both ways as some day visits, contained a spectrum of class sizes, and number of classes that were able to attend the sessions. In this pilot programme classes and student numbers ranged from a single class with six students, up to and including 5 classes and 150 students in a single day. This was very unexpected, in particular the very small and very large classes and student numbers. Perhaps if the landing page for the booking system was too explicit, for example suggesting 3 classes and a maximum of 30 students per class, this may have discouraged smaller or larger class sizes applying. On a positive note, the number of students who participated in the pilot phase of the outreach programme was 6761 students. The student ages ranged from third class ( 7 - 8 years old) in primary school to sixth year in second level (17 - 18 years old). Future work will contain detailed breakdowns of age and class sizes.

While additional work is currently underway to determine the diversity breakdown in terms of disadvantaged schools and school location during the outreach effort, initial analysis on the number of male and female students in every class has taken place. This method was additional to the research surveys students who participated in the pre-pilot stage completed, as discussed in Section 3.3. In 2018-19, it was found that 2116 male and 2484 female students participated, with a ratio of 46:54 respectively (Figure 5). To date in 2019-20, 627 male and 1150 female students participated, with a ratio of 35:65 respectively (Figure 5). This is very positive given the male bias currently found in CS courses.

\section{LESSONS LEARNED}

With early positive findings such as the gender balance and student uptake, the authors would like to provide some early insights on 


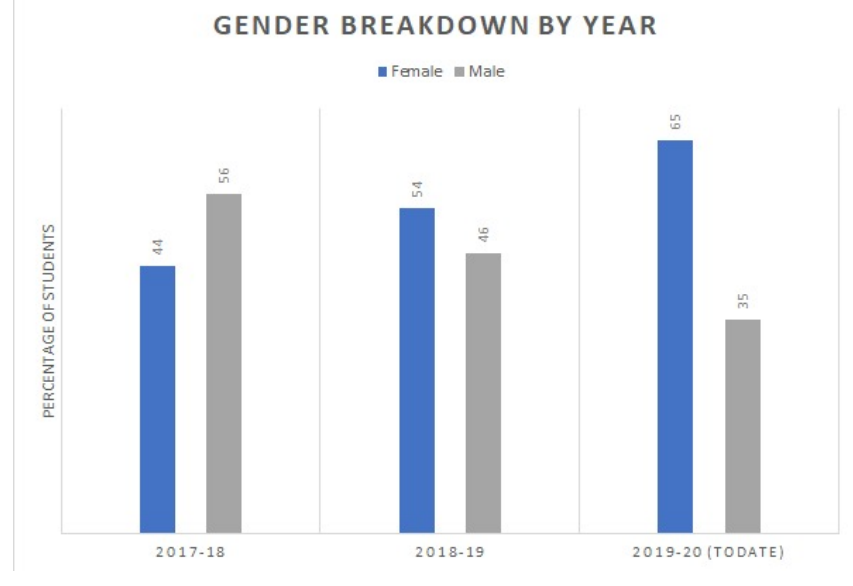

Figure 5: Ratio of female to male participants

lessons learned during this pilot journey. While these are anecdotal, it may provide value for educators considering embarking on, or further developing outreach programmes. This section is presented under two headings: during the outreach programme and administration of the outreach programme.

During the Outreach Programme. Although, currently there is no formal CS education in Ireland open to all students, many still presented varying backgrounds in CS (for example from participation in CoderDojos), with varying levels of ability. During the pre-pilot study the authors incorporated differentiation as a core part of the outreach programme to provide accessibility and appropriate challenges to all learners (for example having variations of the step-counter and wide range of Bebras challenges). The authors believe this was a central component of the outreach programmes success. In addition, teacher buy in was also a vital component of the outreach programme. Early in the pre-pilot programme, teacher attendance was not explicitly requested, and many teachers (perhaps due to CS confidence) opted out of the programme (either not present in the room or concentrated on their work, unaware of the camp). The team noticed where teachers participated (even in a spectator role), the atmosphere in the programme was improved for students, and anecdotally, were more likely to book a follow up session, compared to teachers who did not participate. Thus the team suggest that teachers are present and are encouraged to participate where possible.

Administration of the Outreach Programme. In the pre-pilot year, administration was conducted via email, on a per-request basis. As the programme grew the time required to allocate sessions and dates was unsustainable, requiring several emails to confirm a booking. The outreach team developed a fully automated web based system, that handled the bookings, sent automated email reminders (along with the ethics forms) and confirmed the date and time. This system will be published as an open source project along with the final outreach model. Finally while the automated system was of great value, the three team members realise that (with full time lecturing schedules) with travel time and running up to three sessions a day the longitudinal model is difficult to sustain. Some school visits for a team member began at $5 \mathrm{am}$ and concluded at $8 \mathrm{pm}$. This would be compounded in jurisdictions with significantly larger demographic areas, such as a State in the US. Thus publishing the model for other institutions/interested parties to implement locally is vital to the models future sustainability and success.

\section{CONCLUSIONS \& FUTURE WORK}

This paper describes initial work of the development of a K-12 outreach model. The model was developed over three years, as part of the pilot phase, and the camp content was implemented using a variety of activities. The pre-pilot phase of the model had a reach in 2017-2018 of 2900 students. The pilot phase of the model had a reach in 2018-2019 of 160 schools and 4984 students, and to date in 20192020, 50 schools and 1777 students have been reached. The camps reached a large number of schools with varied socio-economic and gender diversity, along with schools across nearly every county in Ireland. The camps also reached $\sim 2 / 3$ of the new upper second level subject: Computer Science. This was important to the team, as this is the first group to take the new formal curriculum, and experience with this group and research surveys are very valuable for future developments of the model. In addition 3400 surveys were collected with data captured prior to each outreach camp commencing and after it concluded. The data collected in the pilot phase will be used to steer the model, informing camp activities and pedagogical approaches. Early feedback is very positive, from students, teachers and school management. While detailed analysis on the survey data has not yet been performed, the large female participation is a very positive initial finding, with more female students than males taking part in the outreach camps (ratio of 54:46 respectively in 2018-19 and 65:35 respectively to date 2019-20).

The team plan to continue the outreach effort and carry out a longitudinal study (over the next two to five years) on the effectiveness of the outreach programme. The research data collected will be investigated over the coming months and will also be used to iteratively develop the model further. While the results of the model to date have been very positive (numbers and gender uptake for example), the team believe that further refinements can be implemented. Finally, when the model has matured, and developed to a point that has been founded on research, the team plan to share all of this work, nationally and internationally. The team plan to publish the content, methodologies and material developed as part of this model. The group has already expanded to three universities, where it is rare in Ireland to find multiple institutions communicating or even working together in an organised capacity [32]. As it stands it is unsustainable for a single group to continue this level of outreach, thus providing an "out of the box" outreach programme that institutions can implement could help to positively promote the discipline further, and perhaps be of value to the wider computer science education community. In addition with the networks that have been developed the team hope to connect schools and institutions who adopt this model, in an effort to continue this outreach for the schools who participated with us to date.

\section{REFERENCES}

[1] 2019. The Cambridge Dictionary. Cambridge University Press.

[2] Brett A. Becker. 2019. A Survey of Introductory Programming Courses in Ireland. In Proceedings of the 2019 ACM Conference on Innovation and Technology in 
Computer Science Education (ITiCSE '19). ACM, New York, NY, USA, 58-64. https: //doi.org/10.1145/3304221.3319752

[3] Brett A. Becker and Keith Quille. 2019. 50 Years of CS1 at SIGCSE: A Review of the Evolution of Introductory Programming Education Research. In Proceedings of the 50th ACM Technical Symposium on Computer Science Education (SIGCSE '19). Association for Computing Machinery, New York, NY, USA, 338-344. https: //doi.org/10.1145/3287324.3287432

[4] CESI. [n. d.]. Computers in Education Society of Ireland - www.cesi.ie.

[5] Valentina Dagiene and Gerald Futschek. 2008. Bebras International Contest on Informatics and Computer Literacy: Criteria for Good Tasks. In International conference on informatics in secondary schools-evolution and perspectives. Springer, $19-30$.

[6] Adrienne Decker and Monica M. McGill. 2017. Pre-College Computing Outreach Research: Towards Improving the Practice. In Proceedings of the 2017 ACM SIGCSE Technical Symposium on Computer Science Education (SIGCSE '17). ACM, New York, NY, USA, 153-158. https://doi.org/10.1145/3017680.3017744

[7] Adrienne Decker, Monica M. McGill, and Amber Settle. 2016. Towards a Common Framework for Evaluating Computing Outreach Activities. In Proceedings of the 47th ACM Technical Symposium on Computing Science Education (SIGCSE '16). ACM, New York, NY, USA, 627-632. https://doi.org/10.1145/2839509.2844567

[8] Katherine Donnelly. 2018. Dramatic Fall in Number of Students Entering Thirdlevel to Study Computing. Irish Independent (Dec 2018). www.independent.ie/ irish - news / education / dramatic - fall - in - number - of - students - entering thirdlevel-to-study-computing-37605169.html

[9] Mary Anne L. Egan and Timoth Lederman. 2011. The Impact of IMPACT: Assessing Students' Perceptions After a Day of Computer Exploration. In Proceedings of the 16th Annual foint Conference on Innovation and Technology in Computer Science Education (ITiCSE '11). ACM, New York, NY, USA, 318-322. https://doi.org/10.1145/1999747.1999836

[10] Katrina Falkner, Sue Sentance, Rebecca Vivian, Sarah Barksdale, Leonard Busuttil, Elizabeth Cole, Christine Liebe, Francesco Maiorana, Monica M. McGill, and Keith Quille. 2019. An International Benchmark Study of K-12 Computer Science Education in Schools. In Proceedings of the 2019 ACM Conference on Innovation and Technology in Computer Science Education (ITiCSE '19). ACM, New York, NY, USA, 257-258. https://doi.org/10.1145/3304221.3325535

[11] Katrina Falkner, Sue Sentance, Rebecca Vivian, Sarah Barksdale, Leonard Busuttil, Elizabeth Cole, Christine Liebe, Francesco Maiorana, Monica M. McGill, and Keith Quille. 2019. An International Comparison of K-12 Computer Science Education Intended and Enacted Curricula. In Proceedings of the 19th Koli Calling International Conference on Computing Education Research (Koli Calling '19). Association for Computing Machinery, New York, NY, USA, Article Article 4, 10 pages. https://doi.org/10.1145/3364510.3364517

[12] Katrina Falkner, Sue Sentance, Rebecca Vivian, Sarah Barksdale, Leonard Busuttil, Elizabeth Cole, Christine Liebe, Francesco Maiorana, Monica M. McGill, and Keith Quille. 2019. An International Study Piloting the MEasuring TeacheR Enacted Computing Curriculum (METRECC) Instrument. In Proceedings of the Working Group Reports on Innovation and Technology in Computer Science Education (ITiCSE-WGR '19). Association for Computing Machinery, New York, NY, USA, 111-142. https://doi.org/10.1145/3344429.3372505

[13] Russell Feldhausen, Joshua Levi Weese, and Nathan H. Bean. 2018. Increasing Student Self-Efficacy in Computational Thinking via STEM Outreach Programs. In Proceedings of the 49th ACM Technical Symposium on Computer Science Education (SIGCSE '18). ACM, New York, NY, USA, 302-307. https: //doi.org/10.1145/3159450.3159593

[14] Daniel D. Garcia, Wei Ding, Joseph Cohen, Barbara Ericson, Jeff Gray, and Dale Reed. 2015. One-Day Activities for K-12 Face-to-Face Outreach. In Proceedings of the 46th ACM Technical Symposium on Computer Science Education (SIGCSE '15). ACM, New York, NY, USA, 520-521. https://doi.org/10.1145/2676723.2677337

[15] Alka Harriger, Alejandra J Magana, and Ryan Lovan. 2012. Identifying the impact of the SPIRIT program in student knowledge, attitudes, and perceptions toward computing careers. In 2012 Frontiers in Education Conference Proceedings. IEEE, 1-6.

[16] Eunjin (EJ) Jung and Xornam S. Apedoe. 2013. Changing Young Women's Perceptions of CS via Outreach. In Proceedings of the 18th ACM Conference on Innovation and Technology in Computer Science Education (ITiCSE '13). ACM, New York, NY,
USA, 333-333. https://doi.org/10.1145/2462476.2465616

[17] Mahmoud Kaddoura. 2013. Think Pair Share: A Teaching Learning Strategy to Enhance Students' Critical T hinking. Educational Research Quarterly 36, 4 (2013), $3-24$.

[18] Shahnaz Kamberi. 2017. Exposing Girls to Computer Science: Does the All-Girl Model Really Work? In 2017 IEEE Integrated STEM Education Conference (ISEC). IEEE, 152-155.

[19] Mark Keenan. 2013. Up to 4,500 Jobs Unfilled Due to Skills Shortage in IT. Irish Independent (May 2013). https://www.independent.ie/irish-news/up-to-4500jobs-unfilled-due-to-skills-shortage-in-it-29289669.html

[20] Antti-Jussi Lakanen, Ville Isomöttönen, and Vesa Lappalainen. 2012. Life Two Years After a Game Programming Course: Longitudinal Viewpoints on K-12 Outreach. In Proceedings of the 43rd ACM Technical Symposium on Computer Science Education (SIGCSE '12). ACM, New York, NY, USA, 481-486. https: //doi.org/10.1145/2157136.2157280

[21] Antti-Jussi Lakanen, Ville Isomöttönen, and Vesa Lappalainen. 2014. Five Years of Game Programming Outreach: Understanding Student Differences. In Proceedings of the 45th ACM Technical Symposium on Computer Science Education (SIGCSE '14). ACM, New York, NY, USA, 647-652. https://doi.org/10.1145/2538862.2538914

[22] Andrew Luxton-Reilly, Simon, Ibrahim Albluwi, Brett A. Becker, Michail Giannakos, Amruth N. Kumar, Linda Ott, James Paterson, Michael James Scott, Judy Sheard, and Claudia Szabo. 2018. Introductory Programming: A Systematic Literature Review. In Proceedings Companion of the 23rd Annual ACM Conference on Innovation and Technology in Computer Science Education (ITiCSE 2018 Companion). Association for Computing Machinery, New York, NY, USA, 55-106. https://doi.org/10.1145/3293881.3295779

[23] Catherine Mooney, Brett A Becker, Lana Salmon, and Eleni Mangina. 2018. Computer Science Identity and Sense of Belonging: a Case Study in Ireland. In Proceedings of the 1st International Workshop on Gender Equality in Software Engineering. ACM, 1-4.

[24] Laurie Murphy, Tammy VanDeGrift, Brad Richards, and Brent Wilson. 2005. Models for Computer Science K-12 Outreach Activities. f. Comput. Sci. Coll. 21, 1 (Oct. 2005), 274-276. http://dl.acm.org/citation.cfm?id=1088791.1088838

[25] Natasha Nesiba, J Dana-Farley, N Muhyi, J Chen, N Ray, and Enrico Pontelli. 2015. Young Women in Computing: Creating a successful and sustainable pipeline. In 2015 IEEE Frontiers in Education Conference (FIE). IEEE, 1-9.

[26] Karen Nolan, Roisin Faherty, Keith Quille, Brett A. Becker, and Susan Bergin. 2019. CSinc: An Inclusive K-12 Outreach Model. In Proceedings of the 19th Koli Calling International Conference on Computing Education Research (Koli Calling '19). Association for Computing Machinery, New York, NY, USA, Article Article 34, 2 pages. https://doi.org/10.1145/3364510.3366156

[27] Vamsi Paruchuri. 2013. Enhancing CS Awareness Among K-12 Students in Central Arkansas. F. Comput. Sci. Coll. 28, 5 (May 2013), 17-23. http://dl.acm.org/ citation.cfm?id=2458569.2458573

[28] Keith Quille, Natalie Culligan, and Susan Bergin. 2017. Insights on Gender Differences in CS1: A Multi-institutional, Multi-variate Study.. In Proceedings of the 2017 ACM Conference on Innovation and Technology in Computer Science Education (ITiCSE '17). ACM, New York, NY, USA, 263-268. https://doi.org/ $10.1145 / 3059009.3059048$

[29] Keith Quille, Roisin Faherty, Susan Bergin, and Brett A. Becker. 2018. Second Level Computer Science: The Irish K-12 Journey Begins. In Proceedings of the 18th Koli Calling International Conference on Computing Education Research (Koli Calling '18). ACM, New York, NY, USA, Article 22, 5 pages. https://doi.org/ $10.1145 / 3279720.3279742$

[30] Majd F Sakr, Khaled A Harras, and Mark Stehlik. 2011. Computer What?! Designing Outreach Activities to Introduce Computer Science to K-12 in Qatar. In 2011 IEEE Global Engineering Education Conference (EDUCON). IEEE, 592-596.

[31] Sue Sentance, Jane Waite, and Maria Kallia. 2019. Teaching Computer Programming With PRIMM: a Sociocultural Perspective. Computer Science Education 29, 2-3 (2019), 136-176. https://doi.org/10.1080/08993408.2019.1608781

[32] Oireachtas Library \& Research Service. 2017. STEM in Schools: The Introduction of Coding and Computer Science/ICT to the Curriculum. Technical Report.

[33] Mary Webb, Niki Davis, Tim Bell, Yaacov J Katz, Nicholas Reynolds, Dianne P Chambers, and Maciej M Sysło. 2017. Computer science in K-12 School Curricula of the 2lst Century: Why, What and When? Education and Information Technologies 22, 2 (2017), 445-468. 